\title{
PARAMETER TEKNIS RANCANGAN STANDAR NASIONAL INDONESIA (SNI) RADAR HUJAN
}

\author{
Technical Parameters of Indonesian National Standard (SNI) Design for Rain Radar
}

\author{
Ajun Tri Setyoko, Endi Hari Purwanto, Reza Lukiawan, Meilinda Ayundyahrini \\ Pusat Riset dan Pengembangan Sumber Daya Manusia - BSN \\ Komplek Puspiptek Gedung 430 Tangerang Selatan, Indonesia \\ e-mail: ajun_ts@bsn.go.id
}

Diterima: 12 Desember 2019, Direvisi: 10 Februari 2020, Disetujui: 27 November 2020

\begin{abstract}
Abstrak
Lembaga Antariksa dan Penerbangan Nasional (LAPAN) telah berhasil mengembangkan teknologi $X$-band radar kapal menjadi radar deteksi hujan. Saat ini LAPAN sedang menyiapkan usulan standar terkait spesifikasi teknis radar hujan. Penelitian ini bertujuan untuk mengidentifikasi pemahaman stakeholder atas usulan standar serta mengetahui tingkat kepentingan penerapan parameter teknis standar bagi pengguna radar hujan. Metode yang digunakan pada penelitian ini adalah metode FACTS (Framework for Analysis, Comparison, and Testing of Standard). Ruang lingkup penelitian ini dibatasi pada analisis stakeholder, analisis parameter teknis dan analisis perbandingan standar internasional. Penelitian ini melibatkan 10 responden sebagai stakeholder yang terdiri dari instansi pemerintah, para ahli/pakar dan akademisi dari beberapa perguruan tinggi sebagai stakeholder pengguna dan pengembang yang berkecimpung di bidang instrumen radar. Seluruh responden setuju bahwa keberadaan radar di Indonesia sangat penting sehingga Indonesia membutuhkan lebih banyak radar untuk menunjang operasional MEWS (Missile Early Warning System). Seluruh responden juga setuju bahwa diperlukan pengembangan radar hujan yang murah, akurat dan handal yang terstandar. Mayoritas responden menyatakan setuju terhadap 15 butir parameter teknis yang diusulkan sebagai standar radar hujan. Responden mengusulkan agar mempertimbangkan untuk memasukkan parameter teknis standar internasional radar pada usulan SNI radar hujan. Terdapat 4 kriteria parameter fundamental radar yang dipersyaratkan pada standar internasional yaitu sensitivitas, resolusi spasial, ketepatan kecepatan dopler dan durasi pengukuran polarisasi ganda. Disamping itu standar ini mempersyaratkan 8 parameter kunci lainnya yaitu lobus samping antena, lobus rentang samping, kecepatan rotasi maksimum, percepatan, antena penunjuk akurasi, beam direction co-alignment, pencocokan lebar beam, rentang dinamis, emisi yang tidak diinginkan.
\end{abstract}

Kata kunci: SNI, radar hujan, $X$-band

\section{Abstract}

Indonesian National institute of Aeronautics and Space (LAPAN) has successfully developed the ship's Xband radar technology into rain radar. Currently, LAPAN is preparing a standard proposal related to the rain radar technical specifications. This study aims to identify stakeholder understanding of the proposed standard and determine the importance of the application of standard technical parameters for rain radar users. This study using FACTS (Framework for Analysis, Comparison, and Testing of Standards) method. The scope of this study is limited to stakeholder analysis, technical parameter analysis and comparative analysis to international standards. In this study involving 10 respondents as stakeholders consisting of government, experts and academics from several universities as user and developers in the field of radar instruments. All respondents agreed that the presence of radar in Indonesia is very important so that Indonesia needs more radar to support the MEWS (Missile Early Warning System). All respondents also agreed that the development of standardized, accurate and reliable rain radar was needed. The majority of respondents agreed with the 15 technical parameters proposed as rain radar standards. Respondents propose to consider incorporating radar technical parameters in international standards in the proposed SNI rain radar. There are 4 fundamental criteria for radar parameters required in international standards, namely sensitivity, spatial resolution, the precision of Doppler velocity and accuracy of dual polarisation measurement. This standard requires 8 other key parameters namely antenna side lobes, range side lobe, maximum rotation speed, acceleration, antenna pointing accuracy, beam direction co-alignment, beamwidth matching, dynamic range, unwanted emissions. 
Keywords: standardization, rain radar, X-Band

\section{PENDAHULUAN}

Indonesia merupakan wilayah dengan aktivitas konvektif yang tinggi sehingga sering mengakibatkan hujan dan tak jarang terjadi hujan dengan intensitas tinggi. Hujan dengan intensitas lebat berpotensi mengakibatkan bencana hidrometrologi, terutama di wilayah yang rentan terhadap bencana banjir dan tanah longsor. Oleh karena itu, diperlukan adanya upaya pendeteksian dini terhadap faktor-faktor penyebab timbulnya banjir dan tanah longsor. Salah satu upayanya adalah pemantauan intensitas hujan yang terjadi di wilayah Indonesia secara terus menerus. Berbagai teknologi telah dikembangkan untuk pemantauan intensitas hujan, diantaranya radar cuaca dan satelit (Sepriando \& Trisantikawaty, 2016). Indonesia melalui Badan Meteorologi dan Geofisika (BMKG) pada tahun 2016 telah memiliki 40 perangkat radar cuaca yang tersebar di seluruh wilayah Indonesia dengan komposisi sebagai berikut 20 unit produk Enterprise Electronic Corporation (EEC), 15 unit produk Gematronik, 4 unit produk Baron dan 1 unit produk Vaisala. Berdasarkan jenis gelombang, radar cuaca BMKG terdiri dari 39 unit tipe $\mathrm{C}$-band single polarization dan 1 unit tipe X-band dual polarization (Permana et al., 2016). Teknologi radar cuaca ini cakupannya lebih sempit dibandingkan teknologi satelit, namun mempunyai resolusi yang tinggi dan dapat dipasang di daerah manapun yang rawan banjir dan tanah longsor. Akan tetapi teknologi radar cuaca yang ada saat ini masih sangat mahal, untuk itu diperlukan solusi alternatif teknologi radar cuaca yang murah dan handal (Ari, Awaludin, Rahayu, \& Sains, 2012)

Saat ini LAPAN telah berhasil mengembangkan teknologi $X$-band radar kapal menjadi radar deteksi hujan. Radar $X$-band Furuno M1932MK2 merupakan radar navigasi yang dapat dimodifikasi menjadi radar cuaca untuk wilayah lokal. Radar ini merupakan radar yang dipakai di kapal laut untuk mendeteksi kapal lain dan daratan yang ada disekitarnya. Radar ini memiliki transmisi frekuensi pada rentang $X$-band dengan panjang gelombang 3,75-2,5 cm yang mampu mendeteksi tetes hujan namun dengan cakupan wilayah yang masih rendah (sekitar 0-60 km). Prinsip kerja radar ini yaitu dengan memanfaatkan jumlah energi yang dipantulkan oleh partikel tetes hujan untuk suatu sampel volume. Radar navigasi laut Furuno 1932 Mark-2 belum menggunakan teknik doppler dalam pendeteksian targetnya dan harganya jauh lebih murah dibandingkan radar cuaca doppler untuk pemantauan intensitas hujan (Awaludin, Nugroho, \& Rahayu, 2013).

Pemerintah melalui LAPAN saat ini sedang menyiapkan usulan standar terkait spesifikasi teknis radar hujan sebagaimana yang diamantkan dalam UU Nomor 21 Tahun 2013 tentang keantariksaan bahwa perlu adanya metode dan kualitas pengolahan data penginderaan jauh. Pada penelitian ini akan mengidentifikasi pemahaman stakeholder atas usulan standar serta mengetahui tingkat kepentingan penerapan parameter teknis standar bagi pengguna radar hujan. Hasil penelitian ini dapat menjadi masukan dan memberikan manfaat pada pengembangan standar radar hujan untuk memastikan hasil pemantauan hujan yang standar, akurat dan handal, memastikan pengoperasian radar hujan yang aman sehingga mengurangi gangguan terhadap lingkungan, meningkatkan umur peralatan dan mengurangi potensi kerusakan alat serta biaya perbaikan, meningkatkan tingkat keselamatan kerja personil dalam pengoperasian radar, serta terpenting meningkatkan daya saing produk radar hujan Indonesia sehingga meningkatkan daya saing ekonomi.

\section{TINJAUAN PUSTAKA}

Radar (Radio, Detection, and Ranging) mampu mendeteksi target untuk mendapatkan informasi berupa jarak, azimuth, dan kecepatan. Sinyal Radar ada dua jenis, yaitu pulsa (Pulsed Radar) dan gelombang kontinyu (Continuous Wave Radar). Pulsed Radar mempunyai prinsip kerja memancarkan sinyal pulsa dengan PRI (Pulse Repetition Interval) dan PRF (Pulse Repetition Frequency) tertentu dipancarkan dengan modulasi ke dalam sinyal sinusoidal dengan frekuensi yang lebih tinggi serta memanfaatkan delay dari setiap pulsanya untuk mendapatkan informasi dari target. Sedangkan Continuous Wave Radar mempunyai prinsip kerja memancarkan sinyal sinusoidal secara terus menerus dan memanfaatkan sinyal echo yang terdiri dari beberapa variasi frekuensi akibat adanya efek Doppler untuk mendeteksi target. Terdapat beberapa jenis gelombang sinyal radar yang mempengaruhi kemampuan deteksi radar (Gustomo, Fery., 2013). 
Radar meteorologi yang beroperasi pada frekuensi $X$-band memiliki keterbatasan dalam memperkirakan curah hujan karena tingkat atenuasi sinyal radar yang relatif rendah. Namun sedikit modifikasi melalui pendekatan polarimetrik dapat meningkatkan efek atenuasi yang dapat meningkatkan kinerja radar $X$-band untuk memperkirakan curah hujan. Radar $X$-band yang dimodifikasi memiliki beberapa keunggulan dibandingkan radar dengan panjang gelombang yang lebih tinggi. Keuntungannya adalah ukurannya yang relatif kecil sehingga memiliki mobilitas tinggi, harga lebih rendah dan biaya perawatan, kebutuhan daya rendah, potensi resolusi spasial yang tinggi, dan sinyal diferensial fase yang kuat. Ini menjadikan $X$-band radar sangat prospektif untuk dikembangkan untuk mendukung radar cuaca yang saat ini beroperasi (National Research Council, 2004)

Teknologi radar $X$-band telah dikembangkan untuk studi estimasi curah hujan yang dilakukan oleh (Wurman, 1997). Pengujian dan validasi hasil estimasi curah hujan radar $X$-band telah dilakukan oleh (Anagnostou, Anagnostou, \& Kruger, 2004). Gelombang $X$-band polarimetrik adalah alat yang efektif untuk mengambil parameter curah hujan resolusi temporal dan spasial yang tinggi. Validasi kinerja radar $X$-band dilakukan menggunakan alat pengukur hujan dan disdrometer yang terletak di dekat lokasi radar umumnya di kisaran 12-15 km. Dalam pengembangan radar hujan $X$-band masih diperlukan penilaian efektivitas radar $X$-band polarimetrik dalam lingkup yang lebih luas dan jarak yang lebih jauh.

Pengembangan radar hujan $X$-band dengan jaringan sensor yang berbeda dan heterogen untuk memantau dan memperkirakan risiko hidrologi dan aplikasi hidrologi lainnya telah dilakukan di beberapa negara. Di Ekuador, pengembangan radar hujan $X$-band dilakukan dengan memodifikasi radar kapal FURUNO 1525 MK III pada daya keluaran $25 \mathrm{~kW}$. Frekuensi transmisi radar pada $9410 \pm 30 \mathrm{MHz}$ dengan bandwidth $3 \mathrm{MHz}$ dan panjang pulsa pada $1,2 \mathrm{~ms}$ pada tingkat pengulangan pada $600 \mathrm{~Hz}$. Antena memiliki pengaturan waveguide yang ditempatkan sebagai radiator dengan panjang 2,8 $\mathrm{m}$. Sinar utama adalah 0,958 horisontal dan 208 vertikal lebar. Antena berputar pada $24 \mathrm{rpm}$ yang menghasilkan 120 pindaian setiap 5 menit untuk memberikan total gambar akhir. Resolusi sementara dari radar adalah 5 menit (Matrosov, S Y, Kingsmill. D E, Artner, 2005).
Sistem radar ini terdiri dari perangkat keras radar kapal, monitor radar yang dilengkapi dengan dua PC standar dengan sistem operasi DOS menggunakan konverter A/D 10-bit $20 \mathrm{MHz}$. PC ini digunakan sebagai pemroses sinyal yang menerima sinyal video dari monitor radar Furuno dan mengumpulkan informasi arah tambahan. Sinyal dikumpulkan, diproses, dan dikonversi dari kutub ke koordinat kartesius kemudian ditransfer ke PC melalui filter anti-clutter di mana filter median diterapkan dan noise dikurangi jika perlu. Saluran komunikasi radio menghubungkan PC ke gedung stasiun penelitian ECSF (Estacion Cientifica San Francisco) pada ketinggian 1860 mdpl yang telah diatur untuk memungkinkan pemeliharaan jarak jauh dan pemantauan realtime (Matrosov, S Y, Kingsmill. D E, Artner, 2005)

Di Italia, EnviSensTechnologies telah berhasil mengembangkan dan memproduksi radar cuaca $X$-band. Sistem perangkat radar ini menggunakan polarisasi non-Doppler tunggal. Radar diatur dengan jangkauan maksimum 30 $\mathrm{km}$ dan dipasang di pegunungan timur yang menghadap ke kota Palermo (Sisilia). Radar ini telah dilengkapi dengan filter anti-clutter untuk menghilangkan objek selain target. Radar ini mampu menghasilkan peta gambar setiap menit dengan resolusi spasial $60 \mathrm{~m}$ dan kemudian dikirim oleh GPRS ke server pusat untuk diproses secara terbuka dan real-time diterbitkan di web (Conti, Francipane, Pumo, \& Noto, 2015)

Tabel 1 Spesifikasi Radar X-band di Italia (Conti et al., 2015).

\begin{tabular}{lc}
\hline \multicolumn{1}{c}{ Parameter } & Nilai \\
\hline Frekuensi transmisi & $9,41 \pm 0,03 \mathrm{GHz}$ \\
Daya puncak & $10 \mathrm{~kW}$ \\
Pulse length & $600 \mathrm{~ns}$ \\
PRF & $800 \mathrm{~Hz}$ \\
Informasi antena & Parabola dengan \\
& ketinggian tetap $\left(2^{\circ}\right)$ \\
& $3,6^{\circ}$ half power beam \\
& width 34 dB \\
\hline
\end{tabular}

Radar berbasis $X$-band juga telah dikembangkan dari modifikasi radar Furuno 1525 di Denmark. Radar ini telah beroperasi sejak 2004 sebagai radar eksperimental dan telah mengalami beberapa perubahan konfigurasi. Konfigurasi ini diperbaiki pada Juli 2008. Aplikasi dan spesifikasi Radar. Radar ini memindai atmosfer dengan sudut bukaan vertikal besar $\pm 10^{\circ}$ secara terus menerus. Volume pengambilan sampel meningkat sebagai fungsi jarak dari radar. Koreksi volume 
eksponensial atau koreksi jarak diproses dalam perangkat lunak (Pedersen, Einar, \& Madsen, 2010).

Tabel 2 Spesifikasi Radar $X$-band di Denmark (Thorndahl \& Rasmussen, 2012).

\begin{tabular}{lc}
\hline \multicolumn{1}{c}{ Parameter } & Nilai \\
\hline Radar & Furuno 1525 \\
Pengembang & $\mathrm{DHI}$ \\
Frekuensi & $9,41 \mathrm{GHz}$ \\
Panjang gelombang & $3,2 \mathrm{~cm}(\mathrm{X}$-band) \\
Daya emisi & $25 \mathrm{~kW}$ \\
Resolusi temporal & $5 \mathrm{~min}$ \\
Resolusi spasial & $500 \times 500 \mathrm{~m}$ (rentang \\
& $60 \mathrm{~km}$ ) \\
& $250 \times 250 \mathrm{~m}$ (rentang \\
& $30 \mathrm{~km}$ ) \\
Rentang kuantitatif & $100 \times 100 \mathrm{~m}$ (rentang \\
Resolusi angular & $15 \mathrm{~km})$ \\
Resolusi vertikal & sekitar $15 \mathrm{~km}$ \\
Rotasi & $0,95^{\circ}$ azimut \\
\hline
\end{tabular}

Di Prancis, pengembangan radar cuaca lokal telah dilakukan dengan menggunakan radar polarisasi ganda $X$-band. Radar ini memiliki antena dengan panjang 1,2 $\mathrm{m}$ dan menggunakan teknologi ganda dengan polarisasi simultan transmisi H\&V. Radar ini melakukan pemindaian bolak-balik di sektor azimut terbatas pada 75 (antara 200 dan 275 Timur Laut) pada ketinggian tunggal 1,8 meter dan pada kecepatan $3^{\circ}$ per detik. Sistem validasi kinerja radar dilakukan dengan 24 alat pengukur hujan dan 1 disdrometer yang dioperasikan di sektor azimut dengan jarak 25 km dari radar (Moreau, Testud, \& Bouar, 2009).

Di Indonesia, LAPAN telah berhasil mengembangkan teknologi $X$-band radar kapal menjadi radar deteksi hujan. Radar navigasi laut Furuno 1932 Mark-2 adalah radar yang digunakan pada kapal laut untuk mendeteksi kapal lain, daratan maupun benda lain di sekitarnya. Dengan bantuan radar ini, seorang navigator kapal akan mendapatkan rute yang aman dan cepat bagi kapalnya, meskipun di malam hari, cuaca yang berkabut gelap, atau di pelabuhan yang padat kapalnya. Sistem radar navigasi laut terdiri dari unit scanner dan unit display. Unit scanner merupakan sistem transceiver yang tersusun dari antena, $\mathrm{Tx} / \mathrm{Rx}$ Switching, magnetron, modulator, limiter, Microwave Integrated Circuit (MIC), dan IF amp. B.

\section{METODE PENELITIAN}

Metode yang digunakan pada penelitian ini adalah metode FACTS (Framework for Analysis, Comparison, and Testing of Standard). NIST (National Institute of Standards and Technology) telah mengembangkan metode yang mencakup tahap pengembangan standar hingga implementasi standar, yaitu FACTS. Metode FACTS sendiri memiliki beberapa tahapan, yaitu analisis stakeholder, analisis parameter teknis, analisis perbandingan standar internasional, dan pengujian standar. Ruang lingkup penelitian ini dibatasi pada analisis stakeholder, analisis parameter teknis dan analisis perbandingan standar internasional.

Data yang diperlukan dalam penelitian ini adalah data primer dan data sekunder. Data primer diperoleh langsung dari jawaban isian kuesioner oleh responden yaitu mengetahui pemahaman umum dan dukungan terhadap usulan standar, tingkat persepsi terhadap parameter teknis yang diusulkan dalam rancangan standar. Data sekunder diperoleh melalui studi literatur yaitu berupa dokumen rancangan standar radar hujan, jurnal-jurnal nasional dan internasional. Metode analisis yang digunakan dalam penelitian ini adalah metode analisis deskriptif kuantitatif untuk menjawab tujuan memetakan kesiapan infrastruktur standardisasi dari sisi pemahaman stakeholder atas usulan standar serta validasi dan veridikasi untuk mengetahui tingkat kepentingan penerapan parameter teknis standar bagi pengguna data penginderaan jauh. Sehingga diharapkan penelitian yang dilakukan dapat menghasilkan output berupa standar (SNI) yang mendukung tugas dan fungsi LAPAN.

\section{HASIL DAN PEMBAHASAN}

\section{a. Analisis Stakeholder}

Responden dalam penelitian ini adalah pihakpihak yang memanfaatkan, mengembangkan, menggunakan/user, pakar, akademisi yang berkaitan dengan radar. Teknik pemilihan responden menggunakan teknik purposive sampling dimana kriteria responden disesuaikan dengan tujuan penelitian. Saat ini pakar dan akademisi di bidang instrumentasi radar masih sangat sedikit jumlahnya. Data primer diperoleh dari 10 responden yang 
mewakili kriteria sesuai dengan tujuan penelitian. Responden terdiri dari instansi pemerintah, para ahli/pakar dan akademisi dari beberapa perguruan tinggi sebagai stakeholder pengguna dan pengembang yang berkecimpung di bidang instrumen radar. Responden pada penelitian ini yaitu Pusat Penelitian Elektronika dan Telekomunikasi, Balai Besar Teknologi Modifikasi Cuaca, Institut Teknologi Bandung, Institut Pertanian Bogor, Badan Meteorologi dan Geofisika serta Badan Penanggulangan Bencana Daerah. Daftar responden penelitian dijelaskan pada Tabel 3.

Tabel 3 Identifikasi Responden Instrumentasi Radar (Olah Data, 2019).

\begin{tabular}{|c|c|}
\hline Provinsi & Responden \\
\hline $\begin{array}{l}\text { Tangerang } \\
\text { Selatan }\end{array}$ & $\begin{array}{l}\text { - Balai Besar Teknologi } \\
\text { Modifikasi Cuaca }\end{array}$ \\
\hline Bogor & $\begin{array}{l}\text { - Departemen Geofisika } \\
\text { \& Metrologi IPB }\end{array}$ \\
\hline \multirow[t]{2}{*}{ Bandung } & $\begin{array}{ll}\text { - } & \text { Pusat } \\
\text { Elektronika } & \text { dan } \\
\text { Telekomunikasi LIPI }\end{array}$ \\
\hline & $\begin{array}{l}\text { - Sekolah Tinggi Elektro } \\
\text { dan Informatika ITB }\end{array}$ \\
\hline \multirow[t]{2}{*}{ Surabaya } & $\begin{array}{l}\text { - Stasiun Meteorologi } \\
\text { Kelas I Djuanda }\end{array}$ \\
\hline & $\begin{array}{l}\text { - Badan } \\
\text { Penanggulangan } \\
\text { Bencana Daerah Jawa } \\
\text { Timur }\end{array}$ \\
\hline Bali & $\begin{array}{l}\text { - Stasiun Meteorologi } \\
\text { Kelas I Ngurah Rai }\end{array}$ \\
\hline Manado & $\begin{array}{l}\text { - Stasiun Meteorologi } \\
\text { Kelas I Sam Ratulangi }\end{array}$ \\
\hline Palangkaraya & $\begin{array}{l}\text { - Stasiun Meteorologi } \\
\text { Kelas I Tjilik Riwut }\end{array}$ \\
\hline Papua & $\begin{array}{l}\text { - Stasiun Meteorologi } \\
\text { Kelas I Sentani }\end{array}$ \\
\hline
\end{tabular}

Data primer diperoleh melalui alat bantu kuesioner yang dibagi menjadi 3 bagian pertanyaan yaitu pemahaman umum dan dukungan terhadap usulan standar, tingkat persepsi terhadap parameter teknis dalam standar dan kebutuhan teknis pengembangan standar. Secara umum responden mendukung adanya teknologi radar hujan dan pengembangan standarnya. Hal ini didukung adanya kebutuhan akan radar yang murah dan portable yang dapat menjangkau daerah terpencil.

Data kuesioner memperoleh hasil seluruh responden menyatakan setuju bahwa pengembangan produk radar hujan dapat menjadi solusi alternatif radar yang murah dan handal untuk mendukung radar cuaca dalam memenuhi kebutuhan nasional terhadap alat pemantau hujan, mendukung pemantauan cuaca dan penanggulangan bencana hidrometeorologi. Seluruh responden juga menyatakan setuju bahwa diperlukan standar terkait produk radar hujan sehingga dapat diperoleh data hasil pemantauan hujan yang standar, akurat dan handal sehingga responden menyetujui jika LAPAN mengusulkan rancangan SNI produk radar hujan.

\section{b. Analisis Parameter Teknis}

Pada penelitian ini telah didapatkan beberapa parameter teknis radar hujan yang diusulkan oleh LAPAN untuk dilakukan pengujian standar. Pada tahap pengujian dapat dilakukan dengan beberapa cara, yaitu implementasi parameter kebutuhan stakeholder dalam prototype dengan pengujian laboratorium atau membuat kuesioner parameter kebutuhan teknis sebagai validasi kepada stakeholder. Parameter kebutuhan teknis yang dituangkan kedalam kuesioner terdapat pada Tabel 4.

Tabel 4 Spesifikasi Radar $X$-band Radar LAPAN.

\begin{tabular}{|c|c|c|}
\hline Butir & Parameter & Nilai \\
\hline 1. & Frekuensi kerja & $9.410 \pm 30 \mathrm{MHz}$ \\
\hline 2. & PRF & $600 \pm 22 \mathrm{~Hz}$ \\
\hline 3. & Lebar Pulsa & $0,8 \pm 0,22 \mu \mathrm{s}$ \\
\hline 4. & Duty cycle & $1 \%$ \\
\hline 5. & Rotasi antena & $24 \pm 1 \mathrm{rpm}$ \\
\hline 6. & Resolusi jarak & $120 \pm 3$ meter \\
\hline 7. & $\begin{array}{l}\text { Resolusi } \\
\text { maks. }\end{array}$ & 2 menit \\
\hline 8. & Outdoor enclosure & IP 26 \\
\hline 9. & Indoor enclosure & IP 33 \\
\hline 10. & $\begin{array}{l}\text { Kecepatan } \\
\text { data min. }\end{array}$ & 512 kbps \\
\hline \multirow[t]{2}{*}{11.} & $\begin{array}{l}\text { Temperatur operasional } \\
\text { outdoor }\end{array}$ & $\begin{array}{l}\text { (0 sampai } \\
+55)^{\circ} \mathrm{C}\end{array}$ \\
\hline & $\begin{array}{l}\text { Temperatur operasional } \\
\text { indoor }\end{array}$ & $\begin{array}{l}\text { (+10 sampai } \\
+30)^{\circ} \mathrm{C}\end{array}$ \\
\hline 12. & $\begin{array}{l}\text { Cakupan wilayah } \\
\text { deteksi minimum }\end{array}$ & $40 \mathrm{~km}$ \\
\hline 13. & Power output & $4 \mathrm{~kW}$ \\
\hline 14. & $\begin{array}{l}\text { Lebar pancaran } \\
\text { horizontal maks. }\end{array}$ & $4^{0}$ \\
\hline 15. & $\begin{array}{l}\text { Lebar pancaran vertical } \\
\text { min. }\end{array}$ & $20^{\circ}$ \\
\hline
\end{tabular}

Penelitian ini bertujuan ingin mengetahui seberapa besar tingkat kepentingan penerapan parameter teknis standar bagi stakeholder 
instrumen radar sekaligus untuk mendapat respon atau input komentar atas 15 butir parameter yang diusulkan. Dari hasil pengolahan data primer menyatakan tingkat persepsi pada parameter 1 dengan persentase secara berurutan sebesar $10 \%$ sangat setuju, $80 \%$ setuju, 0\% kurang setuju, 10\% tidak setuju, $0 \%$ sangat tidak setuju. Responden memberikan usulan frekuensi kerja disesuaikan dengan standar internasional 9300-9800 MHz atau peraturan dari Kemenkominfo yaitu 9300$9500 \mathrm{MHz}$ untuk frekuensi kerja $X$-band.

Pada parameter 2 diperoleh hasil responden menyatakan tingkat persepsi dengan persentase secara berurutan sebesar $10 \%$ sangat setuju, $70 \%$ setuju, $10 \%$ kurang setuju, $0 \%$ tidak setuju, $10 \%$ sangat tidak setuju. Responden memberikan usulan nilai PRF $750 \mathrm{~Hz}$ sesuai dengan persamaan perhitungan PRF. Responden juga memberikan usulan rentang PRF yang lebar antara 300$2000 \mathrm{~Hz}$ sesuai dengan standar internasional. Pada parameter 3 diperoleh hasil responden menyatakan tingkat persepsi dengan persentase secara berurutan sebesar $20 \%$ sangat setuju, $60 \%$ setuju, $10 \%$ kurang setuju, $0 \%$ tidak setuju, $10 \%$ sangat tidak setuju.

Pada parameter 4 diperoleh hasil responden menyatakan tingkat persepsi dengan persentase secara berurutan sebesar $10 \%$ sangat setuju, $70 \%$ setuju, $10 \%$ kurang setuju, $0 \%$ tidak setuju, $10 \%$ sangat tidak setuju. Pada parameter 5 diperoleh hasil responden menyatakan tingkat persepsi dengan persentase secara berurutan sebesar $10 \%$ sangat setuju, $60 \%$ setuju, $30 \%$ kurang setuju, $0 \%$ tidak setuju, 10\% sangat tidak setuju. Responden memberikan usulan kecepatan rotasi bisa lebih rendah agar kerja radar dapat lebih ekonomis. Pada parameter 6 diperoleh hasil responden menyatakan tingkat persepsi dengan persentase secara berurutan sebesar $0 \%$ sangat setuju, $80 \%$ setuju, $10 \%$ kurang setuju, $10 \%$ tidak setuju, $0 \%$ sangat tidak setuju.

Pada parameter 7 diperoleh hasil responden menyatakan tingkat persepsi dengan persentase secara berurutan sebesar $10 \%$ sangat setuju, $60 \%$ setuju, $10 \%$ kurang setuju, $10 \%$ tidak setuju, $10 \%$ sangat tidak setuju. Pada parameter 8 dan 9 diperoleh hasil responden menyatakan tingkat persepsi dengan persentase secara berurutan sebesar $10 \%$ sangat setuju, $80 \%$ setuju, 0\% kurang setuju, $10 \%$ tidak setuju, $0 \%$ sangat tidak setuju. Pada butir 10 diperoleh hasil responden menyatakan tingkat persepsi dengan persentase secara berurutan sebesar $10 \%$ sangat setuju, $50 \%$ setuju, $30 \%$ kurang setuju, $10 \%$ tidak setuju, $0 \%$ sangat tidak setuju. Responden mengusulkan agar kecepatan transfer data harus lebih dari 512 kbps yaitu 2 mbps.

Pada parameter 11 diperoleh hasil responden menyatakan tingkat persepsi dengan persentase secara berurutan sebesar $10 \%$ sangat setuju, $90 \%$ setuju, $0 \%$ kurang setuju, $0 \%$ tidak setuju, $0 \%$ sangat tidak setuju. Pada parameter 12 diperoleh hasil responden menyatakan tingkat persepsi dengan persentase secara berurutan sebesar 10\% sangat setuju, $60 \%$ setuju, $30 \%$ kurang setuju, $0 \%$ tidak setuju, $0 \%$ sangat tidak setuju. Pada butir 13, 14 dan 15 diperoleh hasil responden menyatakan tingkat persepsi dengan persentase secara berurutan sebesar $10 \%$ sangat setuju, $60 \%$ setuju, $20 \%$ kurang setuju, $0 \%$ tidak setuju, $10 \%$ sangat tidak setuju. Untuk parameter power output perlu dibatasi pula nilai maksimumnya karena output tegangan yang sangat tinggi dapat mengganggu lingkungan di sekitar radar. Presentase persepsi responden terhadap parameter teknis standar disajikan pada Tabel 5.

Tabel 5 Persentase persepsi responden terhadap parameter teknis standar.

\begin{tabular}{llccccc}
\hline No & \multicolumn{1}{c}{ Butir } & $\begin{array}{c}\text { Sangat } \\
\text { Setuju }\end{array}$ & Setuju & $\begin{array}{c}\text { Kurang } \\
\text { Setuju }\end{array}$ & $\begin{array}{c}\text { Tidak } \\
\text { Setuju }\end{array}$ & $\begin{array}{c}\text { Sangat Tidak } \\
\text { Setuju }\end{array}$ \\
\hline 1. & $\begin{array}{l}\text { Frekuensi kerja } 9.410 \pm \\
\quad 30 \mathrm{MHz}\end{array}$ & $10 \%$ & $80 \%$ & $0 \%$ & $10 \%$ & $0 \%$ \\
2. & PRF $600 \pm 22 \mathrm{~Hz}$ & $10 \%$ & $70 \%$ & $10 \%$ & $10 \%$ & $0 \%$ \\
3. & Lebar pulsa 0,8 $\pm 0,22 \mu \mathrm{s}$ & $20 \%$ & $60 \%$ & 10 & $0 \%$ & $10 \%$ \\
4. & $\begin{array}{l}\text { Duty cycle dalam orde 1 } \\
\text { \%o }\end{array}$ & $10 \%$ & $70 \%$ & $0 \%$ & $10 \%$ & $10 \%$ \\
5. & $\begin{array}{l}\text { Kecepatan rotasi antenna } \\
\text { 24 } \pm \text { rpm }\end{array}$ & $10 \%$ & $60 \%$ & $30 \%$ & $0 \%$ & $0 \%$ \\
6. & $\begin{array}{l}\text { Resolusi jarak 120 } \pm 3 \\
\text { meter }\end{array}$ & $0 \%$ & $80 \%$ & $10 \%$ & $10 \%$ & $0 \%$
\end{tabular}




\begin{tabular}{|c|c|c|c|c|c|c|}
\hline 7. & $\begin{array}{l}\text { Resolusi temporal } \\
\text { maksimum } 2 \text { menit }\end{array}$ & $10 \%$ & $60 \%$ & $10 \%$ & $10 \%$ & $10 \%$ \\
\hline 8. & Outdoor enclosure IP 26 & $10 \%$ & $80 \%$ & $0 \%$ & $10 \%$ & $0 \%$ \\
\hline 9. & Indoor enclosure IP 33 & $10 \%$ & $80 \%$ & $0 \%$ & $10 \%$ & $0 \%$ \\
\hline 10. & $\begin{array}{l}\text { Kecepatan transfer data } \\
\text { (uplink) minimum } 512 \\
\text { kbps }\end{array}$ & $10 \%$ & $50 \%$ & $30 \%$ & $10 \%$ & $0 \%$ \\
\hline \multirow[t]{2}{*}{11.} & $\begin{array}{l}\text { Temperatur operasional } \\
\text { outdoor }(0 \text { sampai }+55)^{\circ} \mathrm{C}\end{array}$ & $10 \%$ & $90 \%$ & $0 \%$ & $0 \%$ & $0 \%$ \\
\hline & $\begin{array}{l}\text { Temperatur operasional } \\
\text { indoor }(+10 \text { sampai } \\
+30)^{\circ} \mathrm{C}\end{array}$ & & & & & \\
\hline 12. & $\begin{array}{l}\text { Cakupan wilayah deteksi } \\
\text { minimum } 40 \mathrm{~km}\end{array}$ & $10 \%$ & $60 \%$ & $30 \%$ & $0 \%$ & $0 \%$ \\
\hline 13. & $\begin{array}{l}\text { Power output minimum } 4 \\
\text { kW }\end{array}$ & $10 \%$ & $60 \%$ & $20 \%$ & $0 \%$ & $10 \%$ \\
\hline 14. & $\begin{array}{l}\text { Lebar pancaran horizontal } \\
\text { maksimum } 4^{\circ}\end{array}$ & $10 \%$ & $60 \%$ & $20 \%$ & $0 \%$ & $10 \%$ \\
\hline 15. & $\begin{array}{l}\text { Lebar pancaran vertikal } \\
\text { minimum } 20^{\circ}\end{array}$ & $10 \%$ & $60 \%$ & $20 \%$ & $0 \%$ & $10 \%$ \\
\hline
\end{tabular}

Beberapa responden memberikan beberapa masukan terkait parameter teknis radar hujan yang diusulkan yaitu:

- Frekuensi kerja disesuaikan dengan standar internasional yaitu 9300-9800 $\mathrm{GHz}$ ataupun peraturan dari Kemenkominfo yaitu $9300-9500 \mathrm{GHz}$

- Responden juga memberikan usulan rentang PRF yang lebar antara 300$2000 \mathrm{~Hz}$ sesuai dengan standar internasional

- Kecepatan rotasi radar bisa lebih rendah agar kerja radar dapat lebih ekonomis

- Batasan maksimum power output radar karena tegangan yang terlau tinggi dapat membahayakan lingkungan sekitar

- Kecepatan transfer data minimal 2 Mbps agar proses pengolahan data lebih cepat

- Lebar pancaran horizontal dibatasi $2^{\circ}$ agar blank area semakin sempit

- Perlu ada sistem dual polarisasi (vertikal dan horizontal) agar data yang dihasilkan semakin akurat

- Standar harus lebih fleksibel memperhatikan pengembangan teknologi yang akan datang.

\section{c. Analisis Standar Internasional}

ISO (International Standard Organization) telah menetapkan ISO 19926-1:2019 Meteorology Weather Radar - Part 1 System Perfomance and Operation. Standar ini membagi radar cuaca menjadi 3 berdasarkan pita frekuensi kerjanya yaitu S-band, C-band dan X-band. Sistem S-band besar dengan rentang pengamatan yang lebar, sedangkan sistem Xband kompak dengan rentang pengamatan yang sempit. Kisaran yang berguna dari radar S-band dan C-band biasanya dibatasi oleh kelengkungan bumi $(\geq 300 \mathrm{~km})$, sedangkan pada $X$-band batas normalnya adalah pelemahan tergantung (50 km hingga $100 \mathrm{~km}$ ). Untuk lebih detail. Tabel 5 menunjukkan tipikal untuk setiap pita frekuensi (ISO, 2019).

Tabel 6 Pita Frekuensi Radar Cuaca (ISO, 2019).

\begin{tabular}{cc}
\hline Pita Frekuensi & Rentang Gelombang \\
\hline S-band & $2700-3000 \mathrm{GHz}$ \\
C-band & $5250-5900 \mathrm{GHz}$ \\
X-band & $9300-9800 \mathrm{GHz}$ \\
\hline
\end{tabular}

Kriteria kinerja sistem radar ditentukan sehingga evaluasi dengan kriteria ini dapat diterapkan pada berbagai jenis radar cuaca untuk memberikan manfaat bagi pengguna karena memudahkan pengguna untuk menulis spesifikasi sistem. Di sisi lain, mengadopsi seperangkat kriteria standar akan menyebabkan persaingan yang adil di antara produsen, karena akan mengecualikan radar dengan kinerja sistem yang tidak memadai dari pasar global. Untuk tujuan ini, kriteria harus dapat diukur dengan cara yang umum untuk semua radar cuaca sebelum dikirim dari pabrik. Sensitivitas, resolusi spasial, akurasi kecepatan Doppler, dan akurasi pengukuran polarisasi ganda dipilih sebagai kriteria teratas yang 
menunjukkan kinerja sistem radar cuaca yang paling khas; ini disebut parameter fundamental. Terdapat 4 kriteria parameter fundamental yang dipersyaratkan pada standar ini yaitu sensitivitas, resolusi spasial, ketepatan kecepatan dopler dan durasi pengukuran polarisasi ganda. Disamping itu standar ini mempersyaratkan 8 parameter kunci lainnya yaitu lobus samping antena, lobus rentang samping, kecepatan rotasi maksimum, percepatan, antena penunjuk akurasi, beam direction co-alignment, pencocokan lebar beam, rentang dinamis, emisi yang tidak diinginkan. Keduabelas parameter ini juga perlu dipertimbangkan untuk dapat dimasukkan ke dalam parameter teknis usulan SNI radar hujan.

\section{KESIMPULAN}

Berdasarkan dari hasil survei yang telah diperoleh 10 responden. Seluruh responden setuju bahwa keberadaan radar di Indonesia sangat penting sehingga Indonesia membutuhkan lebih banyak radar untuk menunjang operasional MEWS (Missile Early Warning System) yang mengemban misi mengurangi risiko kerugian materi dan jiwa diakibatkan oleh kondisi cuaca ekstrim. Seluruh responden juga setuju bahwa diperlukan pengembangan radar hujan yang murah, akurat dan handal yang terstandar. Mayoritas responden menyatakan setuju terhadap 15 butir parameter teknis yang diusulkan sebagai standar radar hujan. Diharapkan usulan parameter SNI radar hujan dapat mempertimbangkan parameter teknis radar pada standar internasional.

\section{UCAPAN TERIMAKASIH}

Kami ingin mengucapkan terima kasih kepada Kementerian Riset dan Pendidikan Tinggi yang telah menyediakan dana untuk penelitian ini melalui Program 2019 INSINAS gelombang pertama. Penulis juga ingin mengucapkan terima kasih kepada pimpinan Badan Standardisasi Nasional (BSN) yang telah memberikan dukungan dalam melakukan kegiatan ini. Ucapan terima kasih juga kami ucapkan kepada peneliti di internal BSN, Pusat Inovasi dan Standar Penerbangan Lapan serta semua pihak yang mendukung penelitian ini.

\section{DAFTAR PUSTAKA}

Anagnostou, E. N., Anagnostou, M. N., \& Kruger, A. (2004). High-Resolution Rainfall Estimation from X-Band Polarimetric Radar Measurements Retrieval of Three-Dimensional Raindrop Size Distribution Using X-Band Polarimetric Radar Data, 7541(November 2015). https://doi.org/10.1175/2010JTECHA1407. 1

Ari, G., Awaludin, A., Rahayu, A., \& Sains, P. (2012). Pemanfaatan Noise Radar Kapal untuk Pemantauan Curah Hujan Wilayah Lokal. Jurnal IImiah Elite Elektro, 3(1), 4348.

Awaludin, A., Nugroho, G. A., \& Rahayu, S. A. (2013). Analisis Kemampuan Radar Navigasi Laut Furuno 1932 Mark-2 untuk Pemantauan Intensitas Hujan. Jurnal Sains Dirgantara, 10(2), 90-103.

Conti, F. Lo, Francipane, A., Pumo, D., \& Noto, L. V. (2015). Exploring single polarization $\mathrm{X}$-band weather radar potentials for local meteorological and hydrological applications. Journal of Hydrology, 531, 508-522.

https://doi.org/10.1016/j.jhydrol.2015.10.0 71

Gustomo, Fery., S. (2013). Analisa Penggunaan Sinyal Radar Bentuk Pulsa dan Gelombang Kontinyu untuk Target Bergerak dengan Model Clutter Terdistribusi Rayleigh. Jurnal Teknik Pomits, 2(2), 235-240.

ISO. (2019). ISO 19926-1:2019 Meteorology Weather Radar - Part 1 System Perfomance and Operation.

Matrosov, S Y, Kingsmill. D E, Artner, B. R. E. M. (2005). The Utility of X-Band Polarimetric Radar for Quantitative Estimates of, 6, 248-262.

Moreau, E., Testud, J., \& Bouar, E. Le. (2009). Advances in Water Resources Rainfall spatial variability observed by X-band weather radar and its implication for the accuracy of rainfall estimates. Advances in Water Resources, 32(7), 1011-1019. https://doi.org/10.1016/j.advwatres.2008.1 1.007

National Research Council. (2004). Flash Flood 
Forecasting over Complex Terrain: With an Assessment of the Sulphur Mountain NEXRAD in Southern California. Academy Press.

Pedersen, L., Einar, N., \& Madsen, H. (2010). Calibration of Local Area Weather Radar - Identifying signi fi cant factors affecting the calibration. Atmospheric Research, 97(1-2), 129-143. https://doi.org/10.1016/j.atmosres.2010.03 .016

Permana, D. S., Climatological, M., Agency, G., Hutapea, D., Climatological, M., Agency, G., ... Assimilation, D. (2016). Pengolahan Multi Data Format Radar Cuaca Menggunakan Wradlib Berbasis Python (Multi Weather Radar Format Data Pengolahan Multi Data Format Radar Cuaca). In Jurnal Meteorologi dan Geofisika (Vol. 17, pp. 157-164). https://doi.org/10.31172/jmg.v17i3.350

Sepriando, A., \& Trisantikawaty, R. (2016). Pengolahan Data Radar Cuaca Format Netcdf Menggunakan Bahasa Program Python PENGOLAHAN DATA RADAR CUACA FORMAT NETCDF MENGGUNAKAN BAHASA PROGRAM PYTHON. Prosiding Workshop Operasional Radar Cuaca, (May 2016).

Thorndahl, S., \& Rasmussen, M. R. (2012). Marine X-band weather radar data calibration. Atmospheric Research, 103, 33-44.

https://doi.org/10.1016/j.atmosres.2011.04 .023

Wurman, J. (1997). The DOW mobile multiple Doppler network. In Preprints, 30th Int. Conf. on Radar Meteorology (pp. 95-97). 
Parameter Teknis Rancangan Standar Nasional Indonesia (SNI) Radar Hujan (Ajun Tri Setyoko, Endi Hari Purwanto, Reza Lukiawan, Meilinda Ayundyahrini) 